Farm animal welfare - who writes the rules?

Occasional Publication No. 23 - British Society of Animal Science 1999

edited by A. J. F. Russel, C. A. Morgan, C. J. Savory, M. C. Appleby and T. L. J. Lawrence

\title{
Environmental conditions within livestock vehicles during the commercial transport of sheep
}

\author{
A. M. Jarvis and M. S. Cockram \\ Department of Veterinary Clinical Studies, University of Edinburgh, Easter Bush Veterinary Centre, Easter Bush, \\ Roslin, Midlothian EH25 9RG
}

\section{Introduction}

The air temperature and relative humidity experienced by sheep during commercial road transport in the UK were recorded to assess whether it was likely that the sheep experienced thermal discomfort due to inadequate ventilation. When sheep are confined in a livestock vehicle, heat and water enter the air space. If the ventilation of the vehicle is inadequate the temperature and humidity could increase and this could affect the welfare of the sheep. When the ambient temperature is greater than about $25^{\circ} \mathrm{C}$ the rate of evaporative water loss by sheep in an attempt to maintain body temperature increases rapidly (Degen and Shkolnik, 1978). If the humidity is also high the ability of sheep to lose heat via evaporative water loss is impaired due to a decreased vapour pressure gradient between respired air and the environment.

\section{Material and methods}

Tinytalk ${ }^{\mathrm{TM}}$ PT-100 temperature loggers (accuracy \pm $0.35^{\circ} \mathrm{C}$ at $25^{\circ} \mathrm{C}$ ) and Tinytalk ${ }^{\mathrm{TM}}$ PT-100 humidity loggers (accuracy $\pm 3 \%$ ) (Orion Components, Chichester Ltd) programmed to record at 12-min intervals were fitted to three-deck livestock transporters used by commercial hauliers for transporting sheep. The livestock transporters were between 12.8 and $13.3 \mathrm{~m}$ in length and $2.45 \mathrm{~m}$ wide. The deck height was between 0.80 and $0.97 \mathrm{~m}$. The area of the ventilation slats on the vehicle sides ranged between 25 and 65 per cent of the floor surface area. The area of ventilation slats on each deck ranged between 2.10 and $4.98 \mathrm{~m}^{2}$. A full load of about 300 sheep was transported on each journey. Data were collected during 10 journeys of between 2.5 and $11 \mathrm{~h}$ duration in the UK between the months of February and September. Five temperature loggers were attached inside the vehicle: at the mid point of each deck and at approximately $1 \mathrm{~m}$ from the front and back of the middle deck. Three humidity loggers were attached next to the temperature loggers on the middle deck. The loggers were attached to the roof (approx. $0.1 \mathrm{~m}$ above sheep head height) mid way between the sides of the vehicle. An additional temperature logger was attached to the outside of the vehicle at the front of the livestock compartment at the level of the middle deck.

\section{Results}

Temperatures within the vehicle typically increased during loading, decreased after the vehicle began to move, remained relatively constant as the journey progressed and increased during stationary periods (Figure 1). Relative humidity typically increased during transport to reach 0.8 to 0.9 saturation after transport of 1 to $2 \mathrm{~h}$ and remained relatively high during stationary periods. When sheep with wet fleeces were loaded, the relative humidity within the vehicle was greater than $0 \cdot 8$. External temperatures recorded during the journeys ranged from -2 to $19^{\circ} \mathrm{C}$. The maximum temperature recorded inside

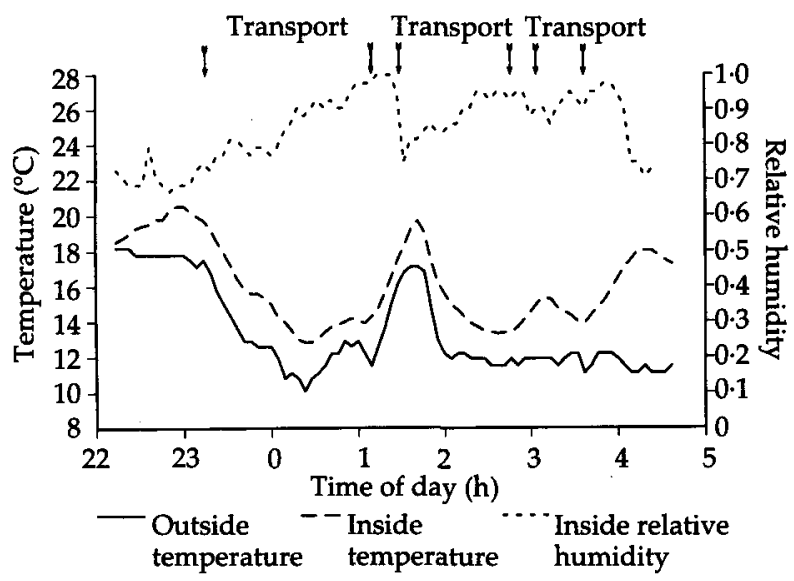

Figure 1 Air temperatures and relative humidity recorded during the commercial transport of sheep in the month of August. Relative humidity was recorded in the front section of the middle deck. Temperature was recorded outside of the vehicle, in the middle section of the lower and upper decks and in the front (F), middle (M) and back (B) sections of the middle deck. The journey involved three periods when the vehicle was moving. These are labelled transport and the arrows indicate the times when the vehicle started and stopped. 
the vehicle during transport was $27^{\circ} \mathrm{C}$ (this occurred immediately after loading and decreased to $23^{\circ} \mathrm{C}$ within $0.5 \mathrm{~h}$ of the journey). A temperature of $22^{\circ} \mathrm{C}$ was recorded inside of the vehicle $1.6 \mathrm{~h}$ after it had stopped for repairs and was fully loaded (the outside temperature was $12^{\circ} \mathrm{C}$ ). The temperature fell to $19^{\circ} \mathrm{C}$ $2.6 \mathrm{~h}$ later but the mean relative humidity during this time was 0.8 (Figure 2). The minimum temperature recorded during transport was $-2^{\circ} \mathrm{C}$. During transport, the mean temperature difference between inside and outside of the vehicle was $0.7^{\circ} \mathrm{C}$ on the lower deck, $0.5^{\circ} \mathrm{C}$ on the middle deck and $0.2^{\circ} \mathrm{C}$ on the upper deck. During transport, the mean temperature difference between inside and outside of the vehicle was $1.1^{\circ} \mathrm{C}$ on the front section of the middle deck, $0.5^{\circ} \mathrm{C}$ on the middle section of the middle deck and $0.9^{\circ} \mathrm{C}$ on the back section of the middle deck. When the vehicle was stationary and loaded with sheep, the mean temperature difference between inside and outside of the vehicle was $1.7^{\circ} \mathrm{C}$ on the lower deck, $3.3^{\circ} \mathrm{C}$ on the middle deck and $1.5^{\circ} \mathrm{C}$ on the upper deck. When the vehicle was stationary and loaded with sheep, the mean temperature difference between inside and outside of the vehicle was $3.0^{\circ} \mathrm{C}$ on the front section of the middle deck, $3.3^{\circ} \mathrm{C}$ on the middle section of the middle deck and $2 \cdot 7^{\circ} \mathrm{C}$ on the back section of the middle deck.

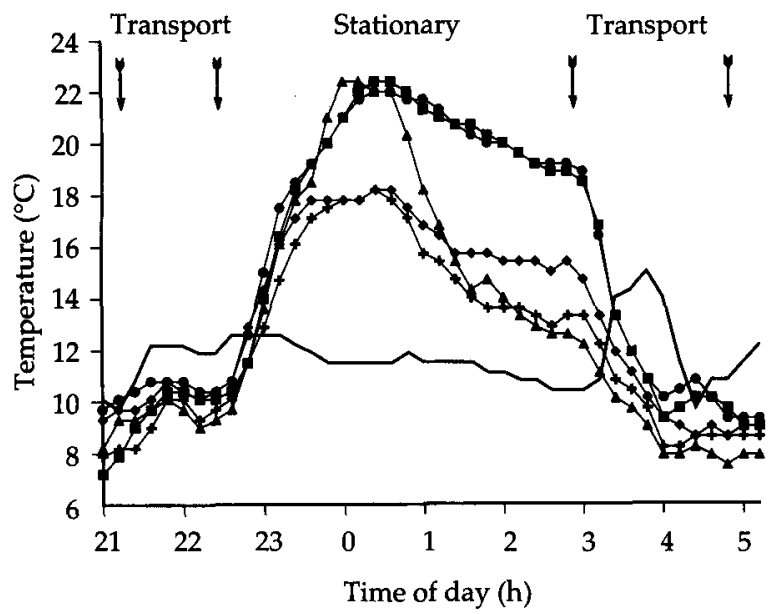

Figure 2 Air temperatures recorded during a commercial journey of sheep involving two periods of transport and one stationary period in the month of March. The arrows indicate the times when the vehicle started and stopped. Temperature was recorded outside of the vehicle, in the middle section of the lower and upper decks and in the front, middle and back sections of the middle deck: - outside; ++ lower middle; middle front; $\longrightarrow$ middle middle; $\longrightarrow-$ middle back; $\longrightarrow$ upper middle.

\section{Discussion}

Air movement during transport is caused by pressure differences between the inside and outside of the vehicle. However, when a vehicle without mechanical ventilation is stationary, air movement within the vehicle is dependent on the convection caused by the animals heating the air, the warmer air rising and cooler air entering through the side inlets and on any external air movement such as wind. Randall and Patel (1994) predicted that the most important factor influencing temperature within a stationary livestock vehicle was the area of the ventilation openings. The stocking density, vehicle size and construction were considered to be less important. The only circumstances in which a sheep may have experienced thermal distress during these journeys due to the air temperature being too cold would be if it had been recently shorn, unable to move away from any draughts or rain near the air inlets, had been starved for several hours or was lying on a cold floor. However, thermal distress during sheep transport can arise if either the temperature or temperature and humidity are too high (Alexander, 1974). During transport, air distribution as measured by air temperature appeared to be reasonably effective. This study did not however include many long journeys at high temperatures in vehicles with limited air inlets.

The most important finding in this study was the high relative humidity recorded during transport. This occurred particularly when sheep with wet fleeces were loaded and when the vehicle was stationary and fully loaded. This indicated that the ventilation was inadequate to remove the moisture produced by the sheep. Although relative humidity decreases within the vehicle as temperature rises, if the moisture load produced by the sheep was combined with high temperatures it could result in the sheep becoming thermally distressed. When environmental temperature rises sheep can increase evaporative heat loss by increased respiration and sweating (Hales and Brown, 1974). The ability to lose heat by this route could be impaired in hot environments when humidity is high and the body temperature and respiration rate of the sheep could rise markedly and panting is likely to occur (Bligh, 1963). Further work is required to evaluate whether sheep exposed to the combinations of temperature and humidity that occur during transport experience thermal distress.

\section{Acknowledgements}

AMJ was supported by a grant from the Royal Society for the Prevention of Cruelty to Animals (RSPCA) and the work was undertaken as part of research projects funded by 
the Scottish Office Agriculture Environment and Fisheries Department and the RSPCA. We are grateful for the help and co-operation that we received from the management and staff of the haulage company.

\section{References}

Alexander, G. 1974. Heat loss from sheep. In Heat loss from animals and man: assessment and control (ed. J. L. Monteith and L. E. Mount), pp. 173-203. Butterworths, London.
Bligh, J. 1963. The receptors concerned in the respiratory response to humidity in sheep at high ambient temperature. Journal of Physiology 168: 747-763.

Degen, A. A. and Shkolnik, A. 1978. Thermoregulation in fat-tailed awassi, a desert sheep, and in German mutton Merino, a mesic sheep. Physiological Zoology 51: 333-339.

Hales, J. R. S. and Brown, G. D. 1974. Net energetic and thermoregulatory efficiency during panting in sheep. Comparative Biochemistry and Physiology 49A: 413-422.

Randall, J. M. and Patel, R. 1994. Thermally induced ventilation of livestock transporters. Journal of Agricultural Engineering Research 57: 99-107. 